\title{
Comparative evaluation of two rotary retreatment systems for removal of root canal filling
}

\author{
Evaluarea comparativă a două sisteme rotative de retratament în \\ îndepărtarea materialului de obturaţie de canal
}

\author{
Sânziana Adina Scărlătescu' ${ }^{1}$ Paula Perlea ${ }^{1}$, Irina Maria Gheorghiu², \\ Alexandru A. Iliescu3 ${ }^{3}$, Alina Toma4 \\ ${ }^{1}$ Disciplina de Endodonţie, Facultatea de Medicină Dentară, UMF „Carol Davila“, Bucureşti, România \\ ${ }^{2}$ Disciplina de Odontoterapie Restauratoare, Facultatea de Medicină Dentară, \\ Universitatea de Medicină şi Farmacie „Carol Davila“, Bucureşti, România \\ ${ }^{3}$ Disciplina de Reabilitare Orală, Facultatea de Medicină Dentară, \\ Universitatea de Medicină şi Farmacie, Craiova, România \\ ${ }^{4}$ Practica privată, România
}

\begin{abstract}
The aim of this study was to compare the efficacy of two rotary retreatment systems - ProTaper Universal Retreatment (Dentsply Sirona) and GPR Endostar (Poldent).

Materials and methods. Forty lower premolar canals were shaped by ProTaper next and filled using cold lateral condensation of gutta-percha. These were divided into 2 groups $(n=20)$ according to the retreatment systems. There were assessed the times of retreatment, the accidents that occurred and the quality of retreatment on the x-rays after the procedures.

Results. Protaper system led to a medium retreatment time of 6.15 seconds per canal and $85 \%$ of the canals showed less than $20 \%$ remnants on the canal wall. GPR system led to a medium retreatment time of 7.45 seconds and $70 \%$ of the canals showed less than $20 \%$ remnants.

Conclusion. Within the limitation of this study, ProTaper Universal Retreatment proved to be more rapid and efficient than GPR system.
\end{abstract}

Keywords: retreatment, Ni-Ti rotary instruments, ProTaper Universal Retreatment, GPR Endostar

\section{REZUMAT}

Scopul acestui studiu a fost compararea eficacităţi a două sisteme rotative special concepute pentru îndepărtarea gutapercii din canalele radiculare - Protaper Universal de dezobturare (Dentsply Sirona) şi GPR Endostar (Poldent).

Material şi metodă. 40 de canale ale premolarilor inferiori au fost preparate cu Protaper Next si obturate prin condensare laterala la rece a gutapercii. Acestea au fost împărţite în 2 grupe $(n=20)$ în funcţie de sistemul cu care s-a dezobturat. S-au analizat timpii de dezobturare, accidentele survenite şi calitatea dezobturării pe radiografiile realizate după finalizarea procedurilor de retratament.

Rezultate. Sistemul Protaper a înregistrat un timp mediu de dezobturare de 6,15 minute per canal, iar 85\% din canale au prezentat mai puţin de $20 \%$ material remanent pe pereţii canalelor radiculare. Sistemul GPR a înregistrat un timp mediu de 7,45 minute per canal, iar $70 \%$ din canale au prezentat mai puţin de $20 \%$ material remanent.

Concluzii. Tुinând cont de limitele acestui studiu, sistemul ProTaper Universal de dezobturare s-a dovedit a fi mai rapid şi mai eficient decât sistemul GRP.

Cuvinte cheie: reluarea tratamentului, instrumente $\mathrm{Ni}$-Ti, ProTaper Universal de dezobturare, GPR Endostar 


\section{INTRODUCERE}

Scopul reluării tratamentului endodontic este să elimine sau să reducă substanţial încărcătura microbiană din interiorul canalului radicular. După îndepărtarea materialelor de obturaţie de canal şi prepararea şi curăţarea întregului spaţiu endodontic, sunt necesare o obturaţie radiculară etanşă şi o restaurare coronară adecvată funcţională si estetică.

Gutaperca împreună cu diverşi sigilanţi ai canalului radicular reprezintă cele mai folosite substanţe utilizate în obturaţiile de canal. De-a lungul timpului au fost imaginate diverse tehnici pentru a îndepărta gutaperca şi sealerii din canal (manuale, rotative sau ultrasonice), cu sau fără folosirea solvenţilor. Numeroase studii au arătat că nici una din aceste tehnici nu poate îndepărta în totalitate materialul de obturaţie de canal $(1,2,3)$.

Sistemul Protaper Universal de retratament este intens utilizat pentru înrepărtarea materialelor de obturaţie de canal, iar eficacitatea sa a fost clar dovedită $(4,5)$. Cu toate acestea, în canalele curbe îndepărtarea materialelor de obturaţie şi apoi curăţarea şi prepararea acestora este cu mult mai dificil de realizat decât în cazul celor drepte şi este mult mai probabilă ruperea sau deformarea instrumentarului $(6,7)$.

Setul ProTaper Universal Retreatment (Dentsply Sirona) este format din 3 instrumente (D1, D2 şi D3), ce au pe secţiune o suprafaţă triunghiulară convexă pentru a uşura îndepărtarea materialului de obturaţie. Şanţurile ce se formează sunt concepute şi pentru a elimina resturile în mişcarea de rotaţie (8). Instrumentele au $16 \mathrm{~mm}$ (D1), $18 \mathrm{~mm}$ (D2) şi 22 mm (D3) şi sunt folosite pentru îndepărtarea gutapercii din treimea coronară, mijlocie şi respectiv apicală. Diametrele vârfurilor pentru D1, D2, D3 sunt $0,30 \mathrm{~mm}, 0,25 \mathrm{~mm}$ şi $0,20 \mathrm{~mm}$, cu conicităţi de $9 \%, 8 \%$ şi respectiv $7 \%$. D1 are vârful activ pentru penetrarea iniţială în canalul radicular, în tip ce D2 şi D3 au vârful netăietor.

Un alt sistem de dezobturare este sistemul GPR (Endostar-Poldent), alcătuit din 4 instrumente însemnate cu cercuri albe pe mâner, numărul de cercuri reprezentând dimensiunea acului. Primul instrument are $17 \mathrm{~mm}$, iar următoarele 3 au $23 \mathrm{~mm}$. GPR 1 se foloseşte pentru partea coronară a canalului pentru a îndepărta gutaperca din $1 / 3$ până la $2 / 3$ din canal. Se folosesc apoi următoarele instrumentele în ordine descrescătoare până se ajunge la porţiunea apicală a canalului. Instrumentele se folosesc la motor endodontic cu turaţie cuprinsă între 150 şi $300 \mathrm{rpm}$ conform recomandărilor fabricantului (9).

Scopul acestui studiu este compararea eficacităţii a două sisteme rotative special concepute pentru îndepărtarea gutapercii din canalele radiculare Protaper Universal de dezobturare şi GPR Endostar.

Obiectivele acestui studiu au fost:

1. Urmărirea timpilor de dezobturare folosind cele 2 sisteme

2. Depistarea accidentelor survenite în timpul tratamentului

3. Analiza radiologică a calităţii reluării tratamentului prin cele 2 tehnici de dezobturare.

\section{MATERIAL ŞI METODĂ}

Pentru realizarea acestui studiu s-au folosit 32 de premolari inferiori cu apexurile complet formate şi canalele radiculare drepte. Suprafeţele radiculare au fost curăţate de ţesut moale şi de tartru imediat după extracţie. Toţi dinţii au fost ţinuţi în soluţie de hipoclorit de sodiu concentraţie 3\% timp de 48 ore pentru a fi dezinfectaţi, apoi au fost clătiţi cu apă curentă şi ţinuţi în ser fiziologic pentru restul studiului.

După realizarea cavităţilor de acces, s-a realizat permeabilizarea dinţilor cu ace Kerr file ISO 10 pe toată lungimea canalelor. Lungimea de lucru a fost măsurată ca distanţa dintre vârful cuspidului ocluzal şi foramenul apical, fiind determinată sub control vizual cu un ac Kerr file ISO 15 până acesta a apărut dincolo de apex; a fost măsurată acestă lungime şi prin scăderea a $0.5 \mathrm{~mm}$ a fost stabilit lungimea finală de lucru. Toate canalele au fost preparate folosind instrumente ProTaper Next (Dentsply Sirona) montate la motorul endodontic Entran (W\&H, Austria), cu viteza de turaţie $300 \mathrm{rpm}$. În cursul lărgirii s-au efectuat lavaje cu hipoclorit de sodiu $2,5 \%$ după fiecare ac folosit, iar ca demineralizant s-a folosit gel EDTA 17\%. Canalele au fost lărgite până la o dimensiune apicală de 30.07 (X3), iar cavitaţile de acces au fost închise cu material provizoriu - Citodur Hard (Dorident, Austria). După uscare canalele au fost obturate prin tehnica condensării laterale la rece, folosind cimentul de 
sigilare Adseal (Meta-Biomed). În total au fost prelucrate 40 de canale.

După definitivarea tratamentului şi a obturaţiilor de canal, dinţii au fost radiografiaţi în incidenţă V-O şi M-D, apoi au fost imersaţi în soluţie salină timp de 2 săptămâni, pentru a reproduce aproximativ mediul bucal uman şi a aştepta priza completă a sealerului.

În vederea reluării tratamentului, dinţii au fost împărţiţi în două grupuri diferite cu 16 dinţi fiecare şi 20 canale în total per grupă.

Grupul A - reluarea tratamentului folosind sistemul GPR Endostar

Grupul B - reluarea tratamentului folosind sistemul ProTaper Universal de retratament

Acele GPR au fost folosite într-o manieră crowndown prin mişcări de pensulare laterală. Instrumentele au fost utilizate progresiv, începând cu mărimea $1(17 \mathrm{~mm})$, pentru a îndepărta gutaperca din partea coronară a canalului radicular. S-a avansat în canal cu acele mai subţiri, mărimile 2,3 şi 4 pentru a îndepărta materialul de obturaţie din treimile mijlocie şi apicală, până la atingerea lungimii de lucru. Acele sunt destul de agresive, astfel încât turaţia maximă a motorului endodontic a fost de $300 \mathrm{rpm}$.

$\mathrm{Cu}$ sistemul ProTaper Universal de dezobturare canalele radiculare au fost instrumentate tot în manieră crown-down, la o turaţie de 500 rpm după recomandările producătorului. Acul ProTaper D1 a fost folosit pentru îndepărtarea materialului de obturaţie din porţiunea coronară, în timp ce treimile mijlocie şi apicală au fost instrumentate folosind acele D2 şi D3. D2 şi D3 au fost folosite printr-o mişcare de pensulare cu aplicare de presiune laterală. ProTaper D3 a fost folosit pe toată lungimea de lucru a canalului radicular.

În ambele grupuri, au fost folosite doar acele de dezobturare fără folosirea solvenţilor. În timpul reluării tratamentului s-a făcut lavaje cu hipoclorit de sodiu 2,5\% după fiecare instrument. Acele au fost curăţate de resturi de material înainte de reintroducerea în canal. Retratamentul a fost considerat complet atunci când pe ultimul instrument care a atins lungimea de lucru nu au mai fost observate resturi de gutapercă sau sealer. După ultima instrumentare canalele au fost spălate abundent cu $5 \mathrm{ml}$ hipoclorit de sodiu 2,5\% şi uscate cu conuri de hârtie.

Timpul total, inclusiv irigarea, necesar pentru îndepărtarea materialul din canalul radicular pe toată lungimea de lucru a fost înregistrat pentru fiecare canal folosind un cronometru. Timpul scurs de la începutul îndepărtării materialului de obturaţie până la atingerea lungimii de lucru a fost înregistrat cu T1. Timpul necesar pentru a obţine îndepărtarea satisfăcătoare a gutapercii după atingerea lungimii de lucru (nu a mai fost observată gutapercă pe instrument) a fost înregistrat cu T2. Timpul total pentru realizarea dezobturării a fost calculat ca $\mathrm{T} 1+\mathrm{T} 2$.

După retratament toţi dinţii au fost radiografiaţi din incidenţă mezio-distală, iar analiza rezultatelor s-a făcut pe radiografii. A fost considerată aria totală a canalului ca fiind $100 \%$. Ariile de materiale radioopace au fost exprimate ca procente din aria totală a canalului. Pentru cuantificarea rezultatelor obţinute s-a utilizat o grilă de punctaj stabilită de Kfir şi colab. 2012 (10).

Scorurile au fost împărţite în 3 categorii reprezentative:

- Scor 1 - canal curat (0-5\% din aria canalului acoperită de reziduuri observate pe imaginea radiologică)

- Scor 2 - canal cu reziduuri moderate (6-20\% din aria canalului acoperită de reziduuri observate pe imaginea radiologică)

- Scor 3 - canal cu reziduuri în cantitate mare (peste $21 \%$ din aria canalului acoperită de reziduuri observate pe imaginea radiologică).

\section{Analiza statistică}

Rezultatele au fost exprimate şi analizate comparativ ca număr şi procente ale timpului de lucru şi ale scorurilor obţinute, după acţiunea celor 2 sisteme de dezobturare.

\section{REZULTATE}

Mediile timpului total de atingere a lungimii de lucru în cele două grupuri nu au fost foarte diferite, însă se poate observa că mediile timpilor de lucru la grupul B au fost mai mici comparativ cu mediile timpilor la grupul A (Tabelul 1).

TABELUL 1. Mediile şi valorile maxime şi minime ale timpului total de lucru la cele 2 grupuri

\begin{tabular}{|l|c|c|c|}
\hline $\begin{array}{l}\text { Tehnica de } \\
\text { dezobturare }\end{array}$ & $\begin{array}{c}\text { Medie per } \\
\text { canal }\end{array}$ & $\begin{array}{c}\text { Valoarea } \\
\text { maximă }\end{array}$ & $\begin{array}{c}\text { Valoarea } \\
\text { minimă }\end{array}$ \\
\hline $\begin{array}{l}\text { Grupa A - } \\
\text { sistem GPR }\end{array}$ & 7,45 minute & 9,50 minute & 4,40 minute \\
\hline $\begin{array}{l}\text { Grupa B - } \\
\text { sistem Protaper }\end{array}$ & 6,15 minute & 7,31 minute & 3,56 minute \\
\hline
\end{tabular}




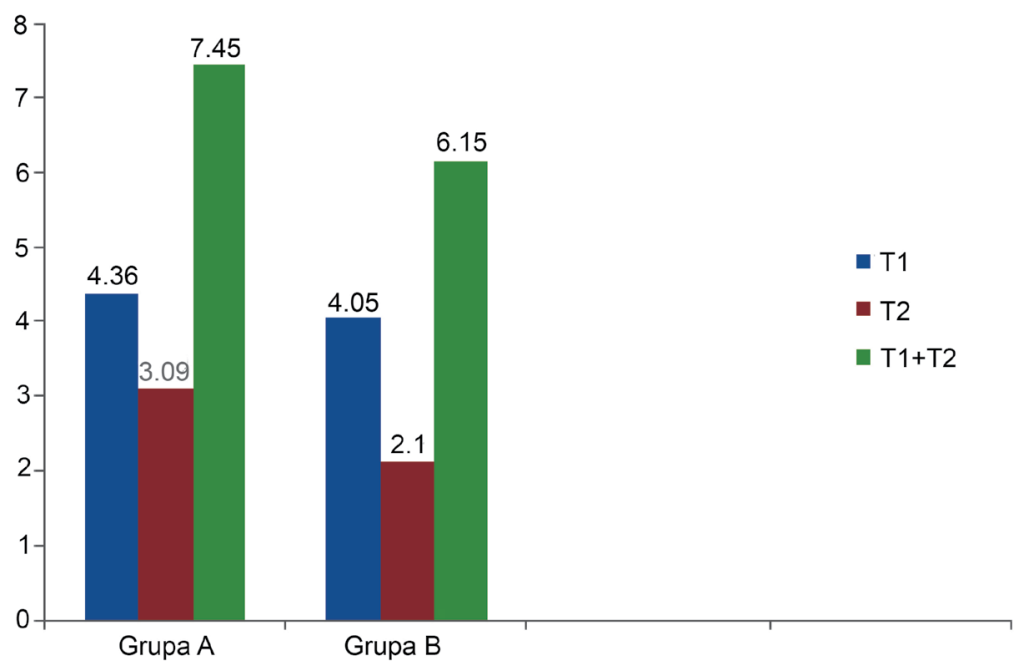

FIGURA 1. Reprezentarea grafică a timpilor de dezobturare Grupa A - sistemul GPR

Grupa B - sistemul ProTaper Universal de dezobturare

Atât timpii parţiali (T1 şi T2), cât şi timpul total de dezobturare (T1+T2) au fost mai mici în cazul grupului B faţă de grupul A (Fig. 1).

Prin analiza radiologică a canalelor instrumentate, s-a putut observa material remanent indiferent de metoda de dezobturare folosită. În funcţie de grila de punctaj stabilită de Kfir şi colab., au fost obţinute următoarele rezultate (Tabelul 2).

TABELUL 2. Scoruri obținute în funcție de cantitatea de material remanent după dezobturare

\begin{tabular}{|l|c|c|c|}
\hline Metoda de dezobturare & Scor $\mathbf{1}$ & Scor $\mathbf{2}$ & Scor $\mathbf{3}$ \\
\hline Grupa A - sistem GPR & $\begin{array}{c}6 \text { canale } \\
(30 \%)\end{array}$ & $\begin{array}{c}8 \text { canale } \\
(40 \%)\end{array}$ & $\begin{array}{c}6 \text { canale } \\
(30 \%)\end{array}$ \\
\hline $\begin{array}{l}\text { Grupa B - sistem ProTaper } \\
\text { Univ. de dezobturare }\end{array}$ & $\begin{array}{c}7 \text { canale } \\
(35 \%)\end{array}$ & $\begin{array}{c}10 \text { canale } \\
(50 \%)\end{array}$ & $\begin{array}{c}3 \text { canale } \\
(15 \%)\end{array}$ \\
\hline
\end{tabular}

După cum se observă, numărul de canale cu scorul 3 din grupa B (peste $21 \%$ din aria canalului acoperită de reziduuri observate pe imaginea radiologică) este de 2 ori mai mic decât cel din grupa A. De asemenea, numărul de canale cu scor $1(0-5 \%$ din aria canalului acoperită de reziduuri observate pe imaginea radiologică) şi scor 2 (6-20\% din aria canalului acoperită de reziduuri observate pe imaginea radiologică) este mai mare în grupul B decât în grupul A. În urma analizei radiologice, am observat că sistemul Protaper Universal de dezobturare a condus spre obţinerea unor canale radiculare mai curate, cu mai puţine materiale remanente pe pereţii canalelor radiculare (Fig. 2a, b, c). Sistemul GPR, deşi eficient şi uşor de manevrat, a condus totuşi spre canale cu mai mult material restant pe pereţii canalelor radiculare (Fig. 3 şi 4).
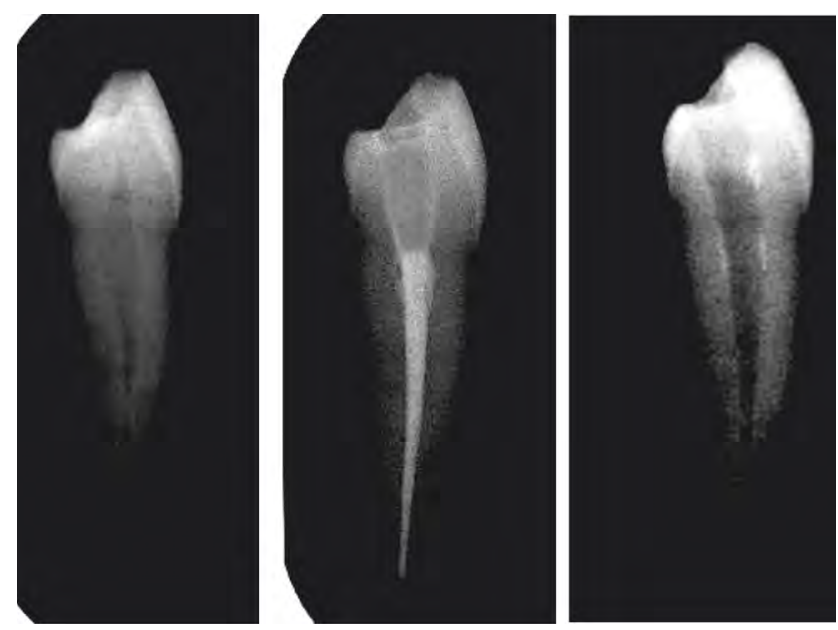

FIGURA 2. Imagine radiologică inițială, după obturația de canal şi după dezobturarea cu sistemul ProTaper Universal de dezobturare (scor 1)

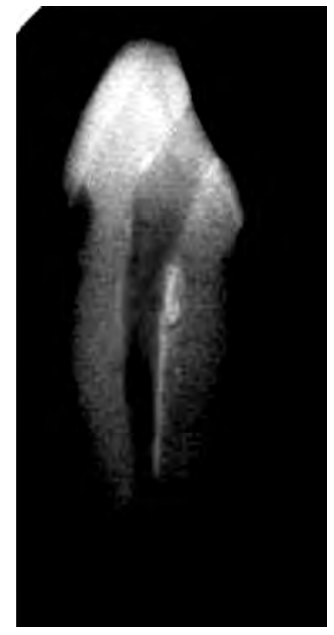

FIGURA 3. Canal dezobturat cu GPR (scor 2)

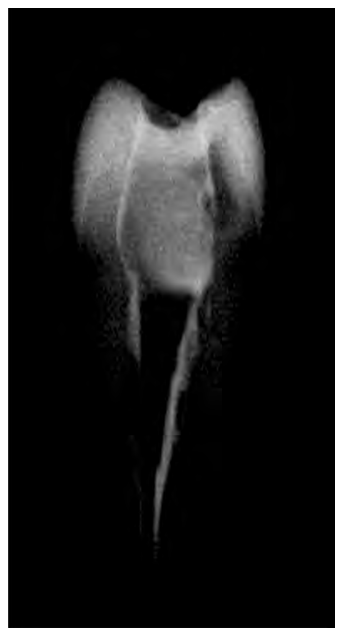

FIGURA 4. Canal dezobturat cu sistemul sistemul GPR (scor 3) 


\section{Accidente înregistrate în timpul dezobturării}

În grupul A în timpul tratamentului s-a înregistrat o fractură verticală a unei rădăcini, în treimea apicală. În grupul B s-a înregistrat fractura unui ac D3. Acesta a fost înlocuit pentru restul grupei cu un ac nou. Nu s-a înregistrat nicio fractură a acelor în grupul A.

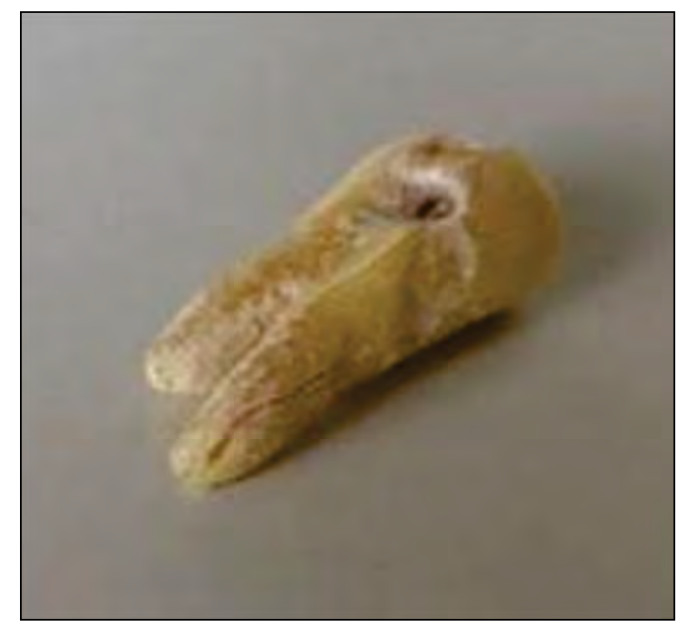

FIGURA 5. Fractură verticală în treimea apicală (sistemul GPR)

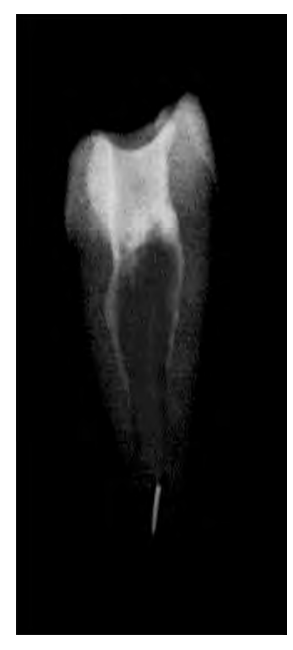

FIGURA 6. Ac D3 fracturat în treimea apicală (sistemul ProTaper de dezobturare)

\section{DISCUṬII}

Motivul principal pentru eşecul unui tratament endodontic îl reprezintă persistenţa microorganismelor la nivelul sistemului endodontic. Premisa pentru succesul reluării tratamentului este reprezentată de îndepărtarea completă a materialului de obturaţie pre-existent (11). În acest studiu s-au comparat două metode rotative de dezobturare sistemul GPR şi sistemul ProTaper Universal de dezobturare.

Pentru evaluarea calităţii îndepărtării materialului de obturaţie pot fi luate în considerare mai mul- te metode. Cele mai comune cuprind secţionarea longitudinală a rădăcinilor, folosirea computer tomografiei sau tehnica de transparentizare a dinţilor. În studiul prezent s-a folosit tehnica radiologică, intens utilizată şi de alte studii $(10,12)$.

\section{Evaluarea timpului de lucru}

Timpul de lucru necesar dezobturării cu sistemul GPR a fost mai mare comparativ cu timpul de lucru realizat cu sistemul ProTaper, atât în ceea ce priveşte timpii parţiali (T1 şi T2), cît şi timpul total de dezobturare. Un motiv pentru această diferenţă de timp ar putea fi numărul mai mare de instrumente - 4 la GPR, faţă de 3 la ProTaper de dezobturare. $\mathrm{Cu}$ toate acestea, timpii de lucru cu cele 2 sisteme au fost destul de apropiaţi.

\section{Evaluarea materialului remanent}

Sistemul ProTaper s-a dovedit a fi mai eficient numărul de canale înregistrat cu scoruri de 1 şi 2 a fost mai mare decât cel înregistrat cu sistemul GPR, iar numărul de canale cu scor 3 a fost pe jumătate faţă de cel înregistrat în cazul sistemului ProTaper Universal de dezobturare. Performanţa mai bună a instrumentelor ProTaper poate fi datorată configuraţiei lor. D1, D2 şi D3 au trei conicităţi şi lungimi progresive. Aceste caracteristici pot permite instrumentelor să taie nu numai gutaperca, dar şi un strat superficial de dentină. De asemenea, acest sistem este capabil să îndepărteze o cantitate mare de material de obturaţie datorită unghiului de tăiere negativ ce nu are o acţiune de netezire a gutapercii, ci de tăiere $(10,12)$.

Instrumentarul rotativ este cel mai indicat pentru îndepărtarea gutapercii din canalele tratate anterior. Însă pentru a preveni fracturarea instrumentelor, ele trebuiesc folosite cu grijă în canale insuficient preparate $(13,14)$. Dificultatea relativă a îndepărtării gutapercii variază în funcţie de lungimea canalului, diametrul transversal al acestuia, calitatea condesării obturaţiei şi curbura canalului. Indiferent de tehnică, gutaperca este cel mai bine îndepărtată progresiv pentru a preveni trecerea iritanţilor periapical (4).

Deşi sistemul ProTaper s-a dovedit mai eficient, şi sistemul GPR a înregistrat rezultate bune. Este posibil ca mişcarea rotativă a acestor instrumente montate la endomotor să producă o cantitate variabilă de căldură datorită fricţiunii, determinând astfel plasticizarea gutapercii, care este mai uşor de 
îndepărtat (10). Rezultatele bune obţinute de sistemul Protaper de dezobturare sunt similare cu cele obţinute în alte studii $(14,15,16)$.

Cum a mai fost demonstrat în studii anterioare, este imposibil de îndepărtat în totalitate gutaperca/ sealer-ul din sistemul endodontic, indiferent de tehnica de retratament folosită $(11,17,18)$. Acest lucru a fost demonstrat şi în acest studiu, având în vedere că niciun specimen nu a fost lipsit de reziduuri.

\section{Evaluarea accidentelor}

În timpul reluării tratamentului cu sistemul GPR a apărut fractura radiculară verticală la 2 canale în treimea apicală. Acest accident poate fi pus atât pe seama agresivităţii instrumentelor, cât şi pe calitatea precară a componentelor radiculare în treimea apicală.

În timpul folosirii sistemului ProTaper a fost înregistrată fractura unui ac D3 în treimea apicală a unui canal. Beasley şi colab., 2013 au raportat frac- turi şi deformări ale acelor D3 în timpul reluării tratamentului canalelor curbe. Această inconvenienţă poate fi datorată conicităţii crescute al instrumentelor şi rotaţiei crescute din timpul preparării, factori ce pot spori oboseala torsională în timpul contactului cu materialul de obturaţie (19).

\section{CONCLUZII}

Niciunul din cele două sisteme nu a îndepărtat în totalitate materialul de obturaţie de pe pereţii canalelor radiculare. Ţinând cont de limitele acestui studiu, sistemul ProTaper Universal de dezobturare s-a dovedit a fi mai rapid şi mai eficient decât sistemul GRP, fapt dovedit prin numărul mai mare de canale cu foarte puţin material remanent la nivelul pereţilor canalelor radiculare.

Notă. Toţi autorii au contribuţii egale în realizarea acestui articol.

\section{BIBLIOGRAFIE}

1. Gu L, Ling J, Wei X, Huang Y. Efficacy of Protaper Universal rotary retreatment system for gutta percha removal from root canals. Int Endod J. 2008; 41:288-295.

2. Tasdemir T, Er K, Yildirim T, Celik D. Efficacy of three rotary NiTi instruments in removing gutta-percha from root canals. Int Endod $J$ 2008; 41, 191-196.

3. Rios MA, Villela AM, Cunha RS, Velasco RC, De Martin AS, Kato AS. Efficacy of 2 reciprocating systems compared with a rotary retreatment system for gutta-percha removal. J Endod. 2014;40:543546.

4. Somma F, Cammarota G, Plotino G, Grande NM, Pameijer CH. The effectiveness of manual and mechanical instrumentation for the retreatment of three different root canal filling materials. J Endod. 2008:34:466-469.

5. Fariniuki LF, Estphaleni VP, Silva-Netoi UX. Efficacy of five rotary systems versus manual instrumentation during endodontic retreatment. Braz Dent J. 2011;22:294-298.

6. Schirrmeister JF, Werbas KT, Meyer KM, Altenburger MJ, Hellwig E. Efficacy of different rotary instruments for gutta-percha removal in root canal retreatment. J of Endod; 2006, 32, 469-472.

7. Barletta FB, Rahde NM, Limongi O, Moura AA, Zanesco C, Mazocatto $\mathrm{G}$. In vitro comparative analysis of 2 mechanical techniques for removing gutta-percha during retreatment. $J$ of Canadian Dental Association 2007; 73, 65-68.

8. Capar ID, Arslan H, Ertas H, G€ok T, Saygılı G. Effectiveness of ProTaper Universal retreatment instruments used with rotary or reciprocating adaptive motion in the removal of root canal filling material, Int Endod J; 2015, 48, 79-83.

9. https://medidentexim.ro/userfiles/39dd3864-ceac-4229-a253a1835c540a3e/File/Catalog_Endostar.pdf.

10. Kfir A, Tsesis I, Yakirevich E, Matalon S, Abramovitz I. The efficacy of five techniques for removing root filling material: microscopic versus radiographic evaluation. Int Endod J. 2012; 45: 35 - 41.

11. Lalit $P$, Godara N, Varma K. Evaluation of efficiency of three NiTi instruments in removing gutta-percha from root canal during retreatment - An in vitro study. JAipur Dental College, 2012: 80-81.

12. Zmener $\mathrm{O}$, Pameijer $\mathrm{CH}$, Banegas $\mathrm{G}$. Retreatment efficacy of hand versus automated instrumentation in oval-shaped root canals: an ex vivo study. Int Endod J. 2006;39:521-526.

13. Unal GC, Kaya BU. A comparison of the efficacy of conventional and new retreatment instruments to remove gutta-percha in curved root canals: an ex vivo study. Int Endod J. 2009;42:344-350.

14. Giuliani V, Cocchetti R, Pagavino G. Efficacy of Protaper Universal retreatment files in removing filling materials during root canal treatment. J Endod. 2008;34:1381-1384.

15. Takahashi CM, Cunha RS, de Martin AS. In vitro evaluation of the effectiveness of Protaper Universal Rotary Retreatment system for guttapercha removal with or without a solvent. J Endod. 2009;35:1580-1583.

16. Mercy J, Jyoti A, Amit M, Murali R, Abhimanyu S, Saangeta T. In vitro evaluation of efficacy of different rotary instrument systems for gutta percha removal during root canal retreatment. J Clin Exp Dent 2016; 8(4), e355-e360.

17. Fonseca de Souza P., Root canal retreament using reciprocating and continuous rotary nickel-titanium instruments, European Journal of Dentistry, 2015: 234-235.

18. Gu L-S, Ling J-O, Wei X., Huang X-Y. Efficacy of ProTaper Universal rotary retreatment system for gutta-percha removal from rool canal, Int Endod J, 2008;41:288-295.

19. 19. Beasley RT, Williamson AE, Justman BC, Qian F.,Time required to remove guttacore, thermafil plus, and thermoplasticized guttapercha from moderately curved root canals with protaper files. $\mathrm{J}$ Endod 2013; 39:125-128. 